\title{
Social Trust of Foreign Teachers amidst Covid-19 Anxiety in XI'AN, China
}

\author{
Karen Joy B. Talidong ${ }^{1}$ \& Edison B. Estigoy ${ }^{2 *}$ \\ ${ }^{1}$ Shaanxi Normal University; \\ ${ }^{2} X i$ 'an International Studies University \\ Corresponding Author*
}

\begin{abstract}
The predicament brought by the COVID-19 pandemic caused many people around the world to deal with anxiety and look for preventive measures at the same time. In this study, social trust is one factor to consider. An online survey was designed to collect the perceptions of the foreign teachers in Xi'an China about social trust, experiences, and attitudes in dealing with anxiety. Results showed that foreign teachers trust the implementation of the preventive measures of COVID-19 by the government which leads to social security and social stability. Further results revealed that foreign teachers are having social trust in the state and community but are undecided in terms of public places. Moreover, regardless of gender, foreign teachers' social trust doesn't differ.
\end{abstract}

Keywords: Social Trust, Social Capital, Preventive Measures, Foreign Teachers, COVID-19 Anxiety

\section{INTRODUCTION}

$\mathrm{C}$ OOVID-19 is an international concern that brought anxiety among people across the globe considering the psychological effects of home quarantines and lockdown leading some individuals to stay away from their family and friends. Although social activities have been restricted in most countries, almost all not essential individual movements were prohibited due to quarantine, while the local hospitals received suddenly thousands of critically ill COVID-19 patients and were forced to implement their emergency protocols [34]. Nevertheless, there are ways of coping with anxiety during the COVID-19 outbreak, maintaining the social connection to friends and families online as well as establishing social trust in the implementation of COVID-19 preventive measures are only a few of the various means of dealing with the pandemic anxiety [14]. Trust is an important factor in internal Social Capital within an organization, leading to greater support and cooperation between individuals [35]. Given the abovementioned concept, social trust is one factor that could ease COVID-19 anxiety among foreign individuals in China; hence, this study aims to seek foreign teachers' perceptions of social trust and ways to deal with the anxiety brought by the pandemic in Xi'an China. Social trust is believed to be the capability of an organization to deal with any crucial situations. Thus, this idea involves various people in society especially leaders who are catalysts of institutional and social stability [3].

\section{A. Literature Review}

Social trust, a belief in the competence, honesty, or benevolence of the other party [16] is known as a crucial cause and consequence of functioning institutions [33]. Thus, the formation and dissolution of social trust have been of primary interest both for analysts and leaders, and many existing literatures have examined the trends, causes, and consequences of social trust and its relationship with institutional effectiveness ([7], [9], [20], [10], [12], [18], and [25]). In terms of the definition of trust, [29] a social psychologist, defined trust as "a conviction that another person will perform certain actions or behave as promised". Trust is important for health at both the individual and societal level, and it is an important component for the smooth functioning of society, as it contributes to the development, maintenance and sustainability of the social quality of people's lives [33]. At both an individual and societal level, trust is important for health and wellbeing and is "fundamental to effective interpersonal relationships and community living" [17].

Trust is essential for the existence of social capital [7] and most authors agree that trust and trustworthiness are at the core of social capital ([22] and [23]). Trust is often mentioned specifically in definitions of social capital, for example, "connections among individuals-social networks and the norms of reciprocity and trustworthiness that arise from them" [25]. Trust is vital for any form of social interaction or exchange and trustworthiness 'lubricates social life' [6]. Effective collective action requires high levels of trust and perceptions of trustworthiness. Trust makes it possible to maintain peaceful and stable social relations that are the basis for collective behaviour and productive cooperation [19]. Social interaction and exchange without trust would be virtually impossible and all economic activity requires at least a minimum level of trust. Without trust actors would not have the confidence that others would uphold their expectations and obligations and would be unwilling to participate with others.

From some theoretical perspectives trust could be considered the acceptance of risk and vulnerability related to the actions of others and an expectation that the other will not exploit this vulnerability [24]. This view is popular in ration-choice approaches that tend to treat trust as a probability and therefore a rational calculation. Gambetta (1988) stated "when we say we trust someone or that someone is trustworthy, we 
implicitly mean that the probability that he will perform an action that is beneficial... is high enough for us to consider in engaging in some form of cooperation with him." [11]. However, rationality is only part of the explanation for trust and trustworthiness since people trust more than is rationally appropriate out of a sense of moral attachment [15]. Institutions can play an important role in perceptions of trust and trustworthiness. Institutions of all types can facilitate the development of shared norms and shared cognitive understandings that provide the foundation for perceptions of trust and trustworthiness. Institutions can mitigate many perceived vulnerabilities, creating confidence in the degree of trustworthiness. These institutional structures help to create and recreate norms and shared understandings.

Torpe and Lolle (2011) compared different measurements of social trust (i.e. trust most people, trust strangers, trust people of another religion, and trust people of another nationality) across the world, and they found that the variable indicating whether "most people can be trusted" has been considered as an indicator of "trust in strangers" in Western countries; while, in China, they found that the majority of Chinese respondents generally trust most people but do not trust strangers, or people with a different nationality or religion.

Bongoh and Hwang (2020) identified the causal effect of a pandemic crisis and institutional responses on social trust. According to the results, trust in South Korean society, people, and the central and local governments improved substantially, whereas trust in judicature, the press, and religious organizations sharply decreased. Improvement in trust in the central and local governments was associated with proactive1. responses to the pandemic crisis, and failure to take appropriate actions was responsible for the deteriorating trust 2 . in religious organizations. The results illustrate the importance of risk management in trust formation and imply that South Korea may be transforming from a low-trust to a high-trust society.

Anxiety is a future-oriented mental state activated by distant and potential threats rather than specific and predictable ones [4]. Anxiety is a basic human emotion consisting of fear and uncertainty that typically appears when an individual perceives an event as being a threat to the ego or self-esteem [28]. Although anxiety is a common mental state in humans, we experience anxiety in a variety of forms. For example, public speaking or leaving one's home can induce anxiety related to a fear of negative evaluation by others and risk of theft, and on the current situation, different anxiety caused by the COVID-19 respectively.

On the study of [1] highlighted the increased anxiety levels that an individual experienced on a regular basis regarding their health, the health of their peers, certain avoidance behaviors as a result of the disease, and behavioral changes of the concerned population. The participants feared going to marketplaces, were concerned for the health of their family members and felt under-confident with the current infection control measures. They were more likely to fear for the safety of their health even at home. Meanwhile, increased levels of anxiety due to use of social media among people below 35 years had resulted in avoidance behaviors. There was a higher tendency for graduates to fear for the safety of their health, even at home. In addition, more than three-fourths of the participants had incorporated changes in their behavior to ensure their safety i.e., reduced physical contact and visits to healthcare facilities, cancelled plans, and washing hands more often.

Considering the global perspective, Philippines, Filipino teachers mostly follow the government policies in dealing with anxiety due to COVID-19 outbreak. The practices include seeking, preventive measures and other coping mechanisms to deal with anxiety during the quarantine period. In the study of Talidong and Toquero (2020) revealed that teachers practice virtual learning, communicate with the professional community, adhere to quarantine requirements, and find purposeful activities to deal with anxiety due to the suspension of national school-related activities brought by the pandemic. As the article points out that there is ample evidence that the Filipino teachers practice measures to deal with anxiety since they adhere to the preventive and educational policies of the government; thus, sustaining the social trust among people and the state.

\section{B. Research Questions}

The following questions guided the development a direction of the present study:

What is the perceived social trust of the respondents toward state, community and Public places amidst COVID-19 anxiety? Is there a significant difference in the perceived social trust toward state, community and public places when the data are grouped according to gender?

\section{METHODOLOGY}

The current investigation employed a quantitative-descriptive design. The study is noted to be quantitative as it intended to appraise or measure the variables accounted for in this current research. Moreover, the study involved the processes of data collection, tabulation, analysis, and description which further justify being a descriptive type of research. An online survey with fourteen statements was designed to collect the perceptions of the foreign teachers in Xi'an China regarding the aspects of social trust: state (five items), community (five items), and public place (five items). These foreign teachers were approached through an online platform specifically QQdocs, a survey tool conveniently available, and the generated link was shared using WeChat, the most popular social media app. The link was also shared personally to the contact list of researchers. They were asked to participate voluntarily in the study. A pilot test was done with fifteen foreign teachers, before the final conduct of the online survey. The online survey was done for the duration of two weeks (October 24 to November 7, 2020) during the post-COVID-19 
outbreak. The gathered data from the research tools were coded to enable analysis through SPSS. Furthermore, sixty responses were analyzed using descriptive statistics specifically the mean percentage. The results were described using an adapted 5-point Likert scale presented below: 4.55.00 Strongly Agree (5), 3.5-4.49 Agree (4), 2.5-3.49 Uncertain (3), 1.5-2.49 Disagree (2), 1.0-1.49 Strongly Disagree (1).

\section{RESULTS AND DISCUSSION}

The responses of the respondents on the questionnaires were all tabulated first in a spreadsheet. Afterwards, the raw data were transferred to SPSS for a descriptive analysis. Table 1.0 provides the analysis, it includes mean score (M), standard deviation (SD), and interpretation.

Table 1: Foreign Teachers' Social Trust

\begin{tabular}{|c|c|c|c|}
\hline Social Trust & Mean & SD & Interpretation \\
\hline State & 4.24 & .423 & Agree \\
\hline Community & 4.23 & .476 & Agree \\
\hline Public Places & 3.13 & .377 & Undecided \\
\hline
\end{tabular}

Social trust and positivity are important factors to deal with anxiety [3]. Based on the grand mean of 4.24 reveals that the Filipino teachers as a whole agree on the statements regarding social trust towards the state. This means that foreign teachers in Xi' an China have trust in the government. A worthy to note among the statements under social trust-state, which is an exception to the general impression, they strongly agree that the "the government is doing its best to ensure public safety during COVID-19 pandemic ( $\mathrm{M}=4.55)$ ". To further support the general mean, responses with agree shows that foreign teachers "satisfied with the implementation of preventive measures and control for COVID-19 (M=4.41) and satisfied with what's happening around in terms of safety and security against COVID-19 (M=4.28)". The satisfactions brought foreign teachers to develop the "sense of social security $(\mathrm{M}=4.14)$ " and even communication barrier is present, respondents "trust the news about the updates on the COVID$19(\mathrm{M}=3.79)$. This is further reinforced by [3] who noted that the leaders of the country are the catalysts of social stability.

Trust can be built within relationships, on a personal basis, but it may also arise outside relationships, more impersonally, on the basis of socialisation and within the context of coordinating institutions [21]. Foreign teacher's perceived social trust toward their community with a general mean of 4.23 and an interpretation of agree. Foreign teachers "have trust in the medical practitioners/team in dealing with the pandemic (M=4.48)" and "confident of the COVID-19 preventive measures in our community $(\mathrm{M}=4.38)$. The trust and confidence brought "trust in the positive progress that our community is doing regarding COVID-19 (M=4.17). Foreign teachers also believe that "people in our community are responsible enough to follow the COVID-19 preventive measures set by the government $(M=4.07)$ and people are cooperative in the guidelines and strict implementation of preventive measures for COVID-19 (M=4.14). Generally, social trust should not be ignored since there is evidence that social trust influences relational trust [26].

However, despite the positive responses as assessed by the Foreign teachers regarding social trust in state and community, responses under social trust in public places shows uncertainties with overall mean of 3.13 with verbal interpretation of undecided. It can be gleaned from the Foreign teachers' responses that they are undecided to have "confidence to go to crowded places $(\mathrm{M}=2.93)$, visiting public places like parks is a risk $(\mathrm{M}=2.93)$, eating in a restaurant is not safe $(\mathrm{M}=2.59)$ and that they feel secured using public transportation $(\mathrm{M}=3.31)$. As assessed by the respondents, they are still undecided in the security to use public transportation like bus, subway, fast train, and plane. These uncertainties are upshot of the COVID-19 preventive measures [14]. However, there is an exception to the general impression to the undecided social trust in public places of the respondents. The exception based on the weighted mean computed to have agree as interpretation which is "I trust that restaurants, malls, and other establishments are doing "disinfection" as prescribed by the authorities ( $\mathrm{M}=3.86)$." The authors ([27] and [35]) suggest that it is important for people to be aware of the preventive measures to avoid transmission of COVID-19 through observing personal hygiene, using sanitizers, washing hands, and wearing masks. This also includes self-isolating, practicing social distancing, and drinking plenty of water [27].

The raw data were computed and analysed. To determine whether there is a significant difference in the social trust in state, community and public places of the respondents when data are grouped according to gender, the inferential statistics known as T-test for independent sample was utilized. Presented in table 2.0 is the analysis.

Table 2.0: Social Trust across Gender.

\begin{tabular}{|c|c|c|c|c|c|}
\hline Social Trust & Gender & Mean & SD & $\begin{array}{c}\mathrm{p}- \\
\text { value }\end{array}$ & Interpretation \\
\hline \multirow{2}{*}{ State } & Male & 4.31 & .37 & \multirow{2}{*}{.301} & \multirow{6}{*}{$\begin{array}{c}\text { Not } \\
\text { Significant }\end{array}$} \\
\hline & Female & 4.20 & .45 & & \\
\hline \multirow{2}{*}{ Community } & Male & 4.25 & .51 & \multirow{2}{*}{.795} & \\
\hline & Female & 4.22 & .46 & & \\
\hline \multirow{2}{*}{ Public places } & Male & 3.18 & .39 & \multirow{2}{*}{.453} & \\
\hline & Female & 3.10 & .37 & & \\
\hline
\end{tabular}

$\mathrm{N}=60$ (22 Males and 38 Females)

Data in Table 2.0 reveals that the Foreign teachers' social trusts are treated for significant difference when grouped by gender, the T-test analysis shows that the probability value at .301 (state), .795 (community) and .453 (public places) are greater than alpha 0.05 with an interpretation of not significant.

This implies that there is no significant difference between the male and female respondents across variables. Therefore, 
gender does not significantly affect foreign teachers' social trust amidst COVID-19 outbreak anxiety and does not differ regardless of gender. This further implies that whatever the gender of the teacher, their social trust in terms of state, community and public places amidst COVID-19 outbreak anxiety do not significantly differ. Regardless of gender, Foreign teachers have positive social trust in the government, equally observe preventive measures in the community and uncertainties when they are in public places amidst COVID-19 outbreak anxiety.

In specific applications, trust is affected by situational factors that interact with individual dispositions [30]. Economists classify trust as decision under strategic uncertainty, arguing that trustworthiness expectations and personal risk attitudes jointly affect particular trust decisions [2]. Studies of gender differences in trust bring mixed findings ([8] and [32]). The result of the study in terms of no gender divide may not support in the recent studies proposing that females show more restrain in response to trust violations [13] while males' trust erodes more strongly following a priming of rationality [5].

\section{CONCLUSIONS}

The attitude of the people in dealing with COVID-19 involves many factors. Yet, social trust is one of the important factors to consider as people need assurance and support from the government leaders. Foreign teachers as respondents add particularity in this study furthering the unprecedented challenges the world is facing. The respondents are more vulnerable in anxieties since the pandemic is still ongoing and in the context of Foreign teachers in Xi'an China, they are far from family and are living in a foreign land. Although in this study social trust is not only solicited from the private or government leaders, it also includes medical practitioners, the community and public places. Social trust leads people to a stable society which implies social security and trust to the leaders of the community and country as a whole. This article points out that the foreign teachers in Xi'an China foster social trust. Therefore, as social trust leads to social security, people are reinforced with the idea that the predicament brought by the pandemic can be resolved which lessens their anxiety. Nonetheless, the study presents social implications that the Foreign teachers have social trust in the government and community in dealing with COVID-19 anxiety in spite of being far from family and not in the home country. Further, the study implies that Foreign teachers' social trust is undecided in public places. Despite the trust given to the government and community, foreign teachers are having uncertainties regarding public places. Moreover, there is no significant difference in the social trust of respondents between males and females. Moreover, further studies should be conducted concerning the same study with a bigger scope of the population as well as showing the relationship of the social trust to dealing with COVID-19 anxiety.

\section{REFERENCES}

[1] Balkhi F, Nasir A, Zehra A, and Riaz R. (May 02, 2020) Psychological and Behavioral Response to the Coronavirus (COVID-19) Pandemic. Cureus 12(5): e7923. doi: $10.7759 /$ cureus.7923

[2] Ben-Ner, A., and Putterman, L. (2001). Trusting and trustworthiness. BUL Rev., 81, 523.

[3] Bongoh Kye, Sun-Jae Hwang (2020), Social Trust in the midst of pandemic crisis: Implications from COVID-19 of South Korea. Research in Social Stratification and Mobility https://doi.org/10.1016/j.rssm.2020.100523

[4] Calhoon, G.G., Tye, K.M., 2015. Resolving the neural circuits of anxiety. Nat. Neurosci. 18, 1394-1404. https://doi.org/10.1038/nn.4101.

[5] Chen, X., and Liu, G. (2017). Gender moderates the effect of homo economicus belief on trust. Social Behavior and Personality: an international journal, 45(5), 873-880.

[6] Cherti, M. (2008). Paradoxes of Social Capital: A MultiGenerational Study of Moroccans in London. Amsterdam University Press

[7] Coleman, J. S. (1990). Foundations of social theory. Harvard University Press

[8] Croson, R., and Gneezy, U. (2009). Gender differences in preferences. Journal of Economic literature, 448-474.

[9] Dalton, R. J. (2007). The social transformation of trust in government. International Review of Sociology, 15(1), 133-154. https://doi.org/10.1080/03906700500038819.

[10] Fukuyama, F. (1995). Trust: the social virtues and the creation of prosperity. Hamish Hamilton

[11] Gambetta, D. (1988). Trust: Making and Breaking Cooperative Relations (Vol. 52, Issue 4).

[12] Glaeser, E. L., Laibson, D. I., Scheinkman, J. A., \& Soutter, C. L. (2000). Measuring trust. The Quarterly Journal of Economics, 115(3), 811-846

[13] Haselhuhn, M. P., Kennedy, J. A., Kray, L. J., Van Zant, A. B., and Schweitzer, M. E. (2015). Gender differences in trust dynamics: Women trust more than men following a trust violation. Journal of Experimental Social Psychology, 56, 104-109.

[14] [14] Karen Joy B. Talidong \& Cathy Mae D. Toquero (2020) Philippine Teachers' Practices to Deal with Anxiety amid COVID-19, Journal of Loss and Trauma, 25:67, 573 579, DOI: $10.1080 / 15325024.2020 .1759225$

[15] Mansbridge, J. (1999). Altruistic trust. In M. E. Warren (Ed.), Democracy and Trust (pp. 290 309). Cambridge University Press cited in Patulny, R. V., \& Lind Haase Svendsen, G. (2007). Exploring the social capital grid: bonding, bridging, qualitative, quantitative. International Journal of Sociology and Social Policy, 27(1/2), 32-51.

[16] McKnight, D. H., \& Chervany, N. L. (2000). What is trust? A conceptual analysis and an interdisciplinary model. AMCIS 2000 Proceedings 382.

[17] Mechanic, D., and S. Meyer. (2000). "Concepts of Trust among Patients with Serious Illness." Social Science and Medicines 51 (5):pp. 657-668

[18] Moy, P., \& Scheufele, D. A. (2000). Media effects on political and social trust. Journalism \& Mass Communication Quarterly, 77(4), 744-759. https://doi.org/10.1177/107769900007700403.

[19] Newton, K. (2001). Trust, social capital, civil society, and democracy. International Political Science Review, 22(2), 201-214

[20] Newton, K. (2005). Predicting cross-national levels of social trust: global pattern or Nordic exceptionalism? European Sociological Review, 21(4), 311-327.https://doi.org/10.1093/esr/jci022.

[21] Nooteboom, B. (2006). Social Capital, Institutions and Trust. CentER Discussion Paper, 200635

[22] Paxton, P. (2002). Social Capital and Democracy: An Interdependent Relationship. American Sociological Review, 67(2), 254-277

[23] Portes, A. (1998). Social capital: its origins and applications in modern sociology. Annual Review of Sociology, 24(1), 1-25 
[24] Purdue, D. (2001). Neighbourhood Governance: Leadership, Trust and $\quad$ Social Capital. Urban Studies, 38(12), 2211-2224

[25] Putnam, R. (2000). Bowling alone: The collapse and revival of American community. New York: Simon \& Schuster.

[26] Robbins, B. G. (2016). From the general to the specific: How social trust motivates relational trust. Social Science Research, 55, 16-30

[27] Roy, D., Tripathy, S., Kar, S. K., Sharma, N., Verma, S. K., \& Kaushal, V.(2020). Study of knowledge, attitude, anxiety, \& perceived mental healthcare need in Indian population during COVID-19 pandemic. Asian Journal of Psychiatry, 51, 102083102087. https://doi.org/10.1016/j.ajp.2020.102083

[28] Sarason, I. G. (1988). Anxiety, self-preoccupation, and attention. Anxiety Research, 1, 3-7.

[29] Taormina RJ. (2013) Measuring trust in China: Resolving Eastern and Western differences in concepts of trust, Third Asian Conference of Psychology and the Behavioral Sciences. 2013. http://hdl.handle.net/10692/310.
[30] Thielmann, I., and Hilbig, B. E. (2015). Trust: An integrative review from a person-situation perspective. Review of General Psychology, 19(3), 249-277.

[31] Torpe L, Lolle H. (2011) Identifying social trust in cross-country analysis: Do we really measure the same? Social Indicators Res. 2011;103:481-500. doi: 10.1007/s11205-010-9713-5.

[32] Van de Walle, S., \& Bouckaert, G. (2003). Public service performance and trust in government: The problem of causality. International Journal of Public Administration, 29 (8 \&9), 891913.https://doi.org/10.1081/PAD120019352.

[33] Ward P, Meyer (2009) S. Trust, social quality and wellbeing: a sociological exegesis. Dev Soc. 2009; 38:339-63.

[34] Wilder-Smith, A., \& Freedman, D. O. (2020). Isolation, quarantine, social distancing and community containment: Pivotal role for oldstyle public health measures in the novel coronavirus (2019-nCoV) outbreak. Journal of Travel Medicine, 27(2), 1-4. https://doi.org/10.1093/jtm/taaa020

[35] Xiang YT, Yang Y, Li W, Zhang L, Zhang Q, Cheung T, et al. (2020) Timely mental health care for the 2019 novel Coronavirus outbreak is urgently needed. Lancet Psychiatry 2020; 7:228-9. 